\title{
Use of Eco friendly traps for the Management of Fruit Flies in Mango - A Success story
}

\author{
Ashish Tyagi*1 ${ }^{1}$, Virendra Pal ${ }^{1}$ and C.S. Prasad ${ }^{2}$ \\ ${ }^{1}$ Krishi Vigyan Kendra, Hastinapur and ${ }^{2}$ Department of Entomology, \\ Sardar Vallabhbhai Patel University of Agriculture \& Technology, Meerut- 250110 \\ *Email: green.ashishtyagi@gmail.com
}

\begin{abstract}
Uttar Pradesh is considered as the main mango producing states having $23.86 \%$ area of the total mango producing area in the country. A large area under Meerut and Saharanpur districts of U.P. has already been declared as important fruit belts of the country due to dense mango orchards. The Oriental fruit fly, Bactrocera dorsalis (Hendel) (Diptera: Tephritidae) is a direct pest on mango. Being a pest of quarantine importance, fruit flies have been considered under top ten world's most serious agricultural pests. The loss in fruit yield ranges from 1 to $31 \%$ with a mean of $16 \%$ in mango. At present, majority of mango growers mainly depend on synthetic pesticides for this pest. Most of the pesticides are more toxic to beneficial insects (such as parasites of pest insects) than to fruit flies and causes several ill effects. Since, the maggots damage the fruits internally; it is not a practical approach to control this pest by using insecticides. Therefore, there is a need to explore alternative methods of control. Kishi Vigyan Kendra, Meerut under Sardar Vallabhbhai Patel University of Agriculture and Technology, Modipuram, Meerut has made sincere efforts to introduce and popularize the recently introduced; Male Annihilation Technique (Use of methyl eugenol based pheromone traps) as an eco friendly, cost effective and feasible approach for the management of fruit flies so that that mango growers may fetch maximum productivity and meet out the required standards of mango export. On an average of the data of three consecutive years during the demonstration of technology at farmer's field, 23 percent increased mango yields was obtained by the farmers which improved their life style and socio economic status.
\end{abstract}

Keywords: Eco-friendly, fruit flies, management, mango, success story.

Paper Cited: Tyagi, A., Pal, V. and Prasad, C.S. (2016). Use of Eco-friendly traps for the Management of Fruit Flies in Mango-A Success story. South Asian Journal of Food Technology and Environment, 2(2): 413-417.

\section{Introduction}

Mango is the most important fruit of India and is known as "King of fruits". The fruit is cultivated in the large area i.e. 2,312 thousand ha and the production is around 15.03 million tons, contributing $40.48 \%$ of the total world production of mango. But infestation with oriental Fruit Fly has been a major impediment to mango export. The emergence of the fruit fly starts from April onwards and maximum population is reached in May-July. Fruit flies proliferate in to the mango fruits through the female one. The female implants its eggs in the young fruits of the host plant, which become attractive as they reach maturity. The larvae or maggots develop in the fresh of untreated fruits by digging tunnels which provide opportunities for secondary infection when the larvae emerge from the fruit. The growth of larvae accelerates maturation of the fruit, which detaches and falls to the ground. Although, several insecticides have been experimented and used for the control of fruit flies over the last 50 years but the internal mode of damage of fruit flies maggots disable the successful management of the pest. Moreover, the ill effects of chemicals i.e resistance to insecticides, pest resurgence, harmful pesticide residues and environmental pollution have proved them a big failure. On the other hand, bait Application Technique (BAT), male Annihilation Technique (MAT), chemical sterilization and botanicals are now being considered as the important alternates of hazardous pesticides for the eco friendly management fruit fly species.

Sardar Vallabhbhai Patel University of Agriculture and Technology is located in Meerut district and surrounded by districts like 
Bulandshahar, Muzaffarnagar, Saharanpur, Baghpat and Meerut, having large area of mango orchards. Moreover, the Kithor and Sahajanpur area under Machhra block in Meerut district and Nakur and Behat blocks of District Saharanpur have already been identified as some of the prominent mango fruit belts of the country. The Farm Science centres (KVKs) working in said districts are supposed to disseminate the technologies / recommendations developed by university in their corresponding area through conducting various extension activities i.e. trainings, trials and demonstrations etc. Therefore, several control tactics have been tested at university level to conclude an eco friendly, cost effective and feasible recommendation for the management of fruit flies so that the mango growers may fetch maximum productivity and meet out the required standards of mango export.

\section{University intervention}

A "National Integrated fruit fly Surveillance project" by Department of Agriculture \& Cooperation, Ministry of Agriculture, Govt. of India was framed and executed during 2006 - 2009 in Saharanpur district with the collaboration of Department of Entomology, Sardar Vallabhbhai Patel University of Agriculture and technology to develop a sustained system of fruit flies surveillance with a view to identify, establish and maintain pest-free areas in line with international/national standards for phytosanitary measures to facilitate trade in agriculture exports. Six thousand five hundred and twenty 6520 (3260 Methyl eugenol +3260 cue lure) "Rakshak traps" were installed at 0.5 , 1.0 and 2.5 Kilometer square grid position according to the density of mango orchards during the project in all eleven blocks of
Saharanpur covering $3283.65 \mathrm{Km} .{ }^{2}$ area of the district.

Rakshak traps having cotton wigs (charged with stock solution containing 6 part alcohol, 4 part Methyl eugenol \& 1 part malathion) were used. Traps were hung on mango tree at a height of $1.5 \mathrm{~m}$ from ground level below the foliage having no direct sunlight. The adult fruit flies were weekly collected, counted and identified during the programme. Although, data of entrapped different species of fruit flies was utilized for the fulfilment

of various objectives of the programme but as far as the direct benefits for mango growers is concern, following were the salient deliverables of the programme:

- Fruit fly catches from 3 zones revealed that 5 species, viz., Bactrocera dorsalis, B. zonata, B. correcta, B. diversa and $B$. cucurbitae were found prevalent in Saharanpur district.

- A total number of 8,69,659 fruit flies of two species i.e. B. dorsalis and B. zonata (mainly responsible for mango and guava yield loss in farmers orchards) were entrapped in 3520 Rakshak pheromone traps covering the mango orchards from 1054 villages of three zones (Behat, Saharanpur and Nakur) of Saharanpur district during October 2007 to August 2008. A huge population of visual trapped fruit flies in pheromone traps in their orchards created keen interest in the technology among farmers and exporters of mango.

- $\quad$ The fruit fly population of $B$. dorsalis and $B$. zonata in each zone was recorded high in the month of July and August however maximum flies were trapped in the month of August. 


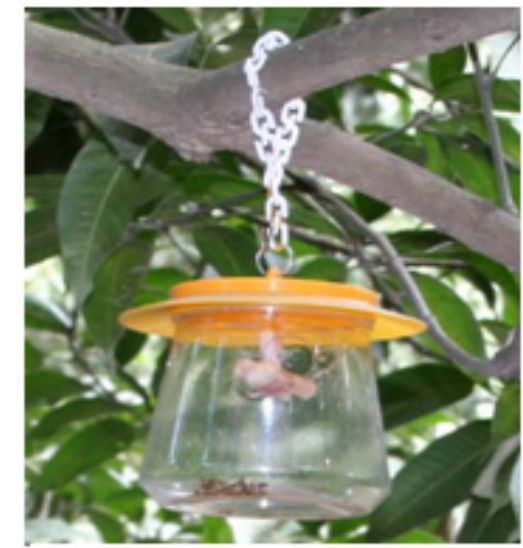

Fig. 1: Rakshak T rap

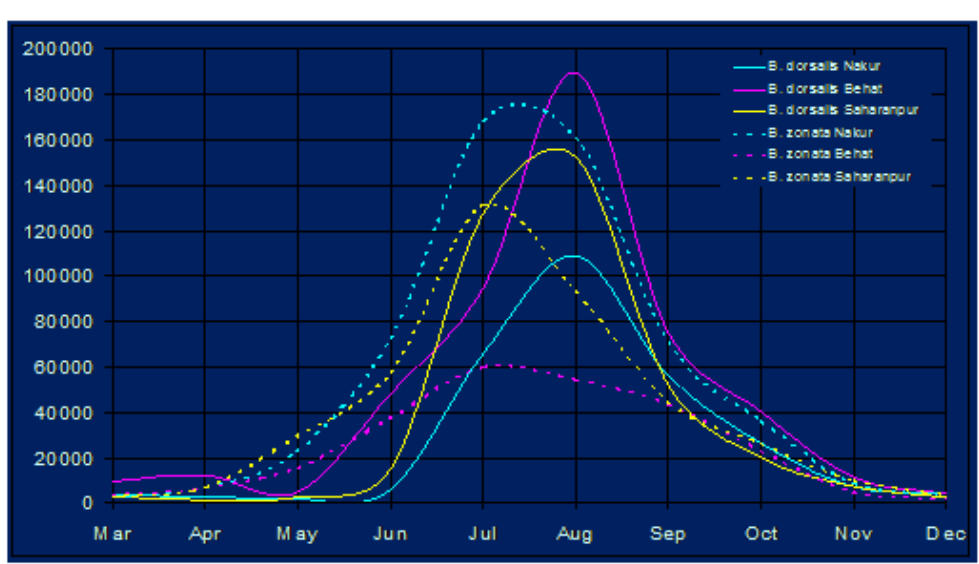

Fig. 2: Graphic al representation of fruit fly occurrence trend is based on 3260 Rakshak traps installed covering all 11 blocks of Sahar anpur according to N.S.P.M. 14.
In Saharanpur district, being one of the major mango fruit belt, the programme was highly appreciated. Progressive farmers / exporters of mango showed their enthusiasm to adopt the technology. Though the installation of traps was restricted to selected fruit orchards as per grid project's limitations, but to satisfy the increasing demand of traps, preparation and installation of homemade traps were advised to the farmers.

"National Integrated fruit fly Surveillance project" was a success not only to fulfil its objectives framed by Department of Agriculture \& Cooperation, Ministry of Agriculture, and Govt of India but also enabled the university to provide the technical recommendation among mango growers for the cost effective and eco friendly management of fruit flies. Moreover, during the course of fulfilling the project's objectives, the technology was well disseminated among the farmers of Saharanpur district.

\section{KVK Intervention}

The collaborative programme was over by the end of year 2009. But the technology was still to be transferred in the major mango producing areas i.e. Kithor, Shahjanpur,Mawana, Behsooma and Jani etc. Krishi Vigyan Kendra, Meerut is also working under the jurisdiction of same agriculture

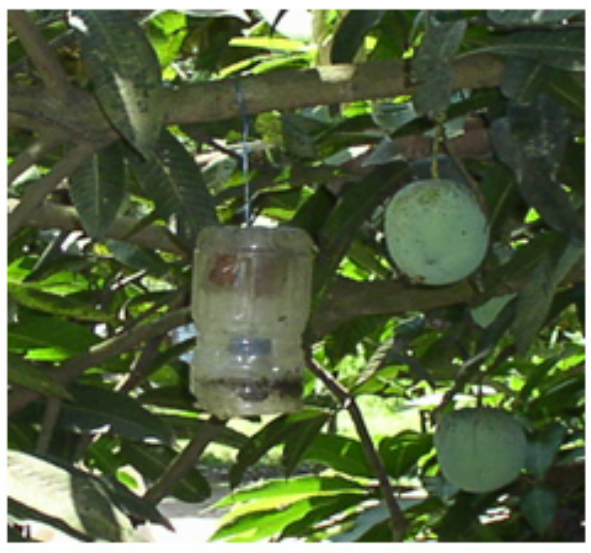

Fig. 3: Homemade Plastic Bottle Trap

university but by then the collaborative programme was no longer in existence for any financial support. Therefore, KVK decided to popularize the technology through its mandatory extension activities i.e. trainings, trials and demonstrations in the district.

\section{Trainings and other extension activities}

Initially, the technology of using Methyl eugenol traps for the management of fruit flies was introduced among farmers under the training programmes conducted by KVK. Various on/off- campus training programmes were organized benefitting 270 mango farmers during 2011-12. The traps were also highlighted through various extension activities like, Kisan Meals, Kisan Goshtis, exhibitions, farmers' seminars, exposure visits, literature, TV talks and Radio talks for wide spread extension of technology. In response, some progressive farmers and mango 
exporters came in contact to $\mathrm{KVK}$ to get the technology demonstrated at their orchards. Scientists of KVK contacted to IISH, Lucknow to get 200 traps and methyl eugenol lures free of cost for demonstration purpose in 2012. KVK organized a special campaign in four villages i.e Samaspur, Hassapur, Khedi manihar and Ganeshpur of Mawana block identifying some progressive farmers for

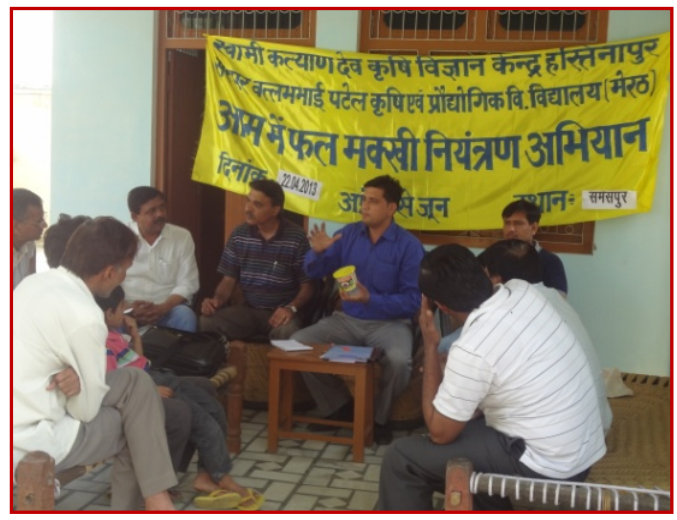

Farmers were impressed to see the huge population of entrapped flies in methyl eugenol traps. The visible impact of performance of these traps also motivated other orchard owners of the village to know about the technology. However, the technology was proved efficient in trapping

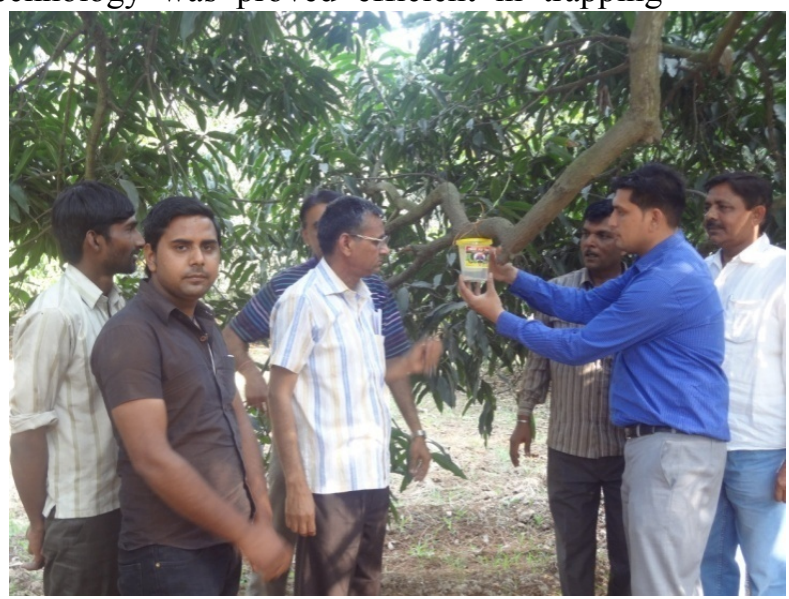

\section{Front Line Demonstrations}

In continuation, $\mathrm{KVK}$ conducted demonstrations selecting 10 farmer's orchards for further dissemination of technology from 2013 onwards. The traps and lure (Methyl eugenol) for fruit fly were procured from PCI, installation of traps @ 7 traps / acre in mango orchards to demonstrate the technology free of cost. The campaign was organized with collaboration with state agriculture department so that proper selection of progressive farmers and monitoring during the demonstration programme may be ensured. An area of 38 acres of mango orchards was covered under this fruit fly management campaign.

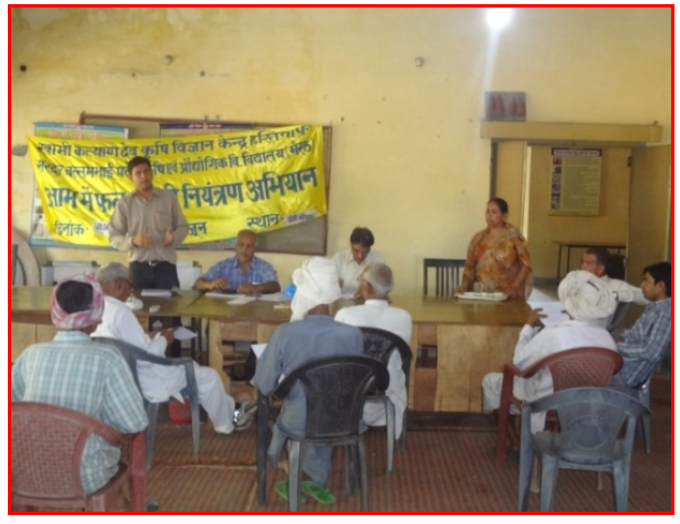

flies but farmers were still in dilemma about the effect of trapped flies on their mango yield. Thus, it was necessary for the scientists to demonstrate the technology in terms of cost benefit ratio and correlation of demonstrated technology with increased yield/income.

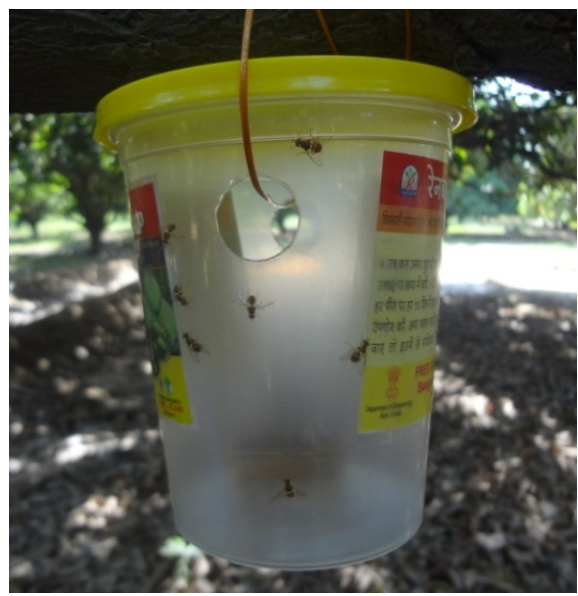

under the front line demonstrations programme of KVK and distributed among 10 farmers for installation @ 7 traps/ acre in Mango orchards during the first fortnight of April month . Lure was replaced once after two months during the month of June. The 
demonstrations continued for three consecutive years covering 30 acre mango orchards dominant area under Machhra, Mawana, Behsuma and Jani blocks of the district.

Results of Front line Demonstration Programme were eye opener for the farmers. As per farmers' feedback, technology was found feasible, cheap and very easily adoptable. On an average of the data of three consecutive years, approximately 23 percent increased mango yields with 1:2.39 cost benefit ratio was obtained by the farmers. Moreover, farmers highly appreciated the technology as they got relief from indiscriminate usage of costly and hazardous pesticides resulting better demand and cost of their produce in market. As a result, in the very next year, many farmers purchased the traps and lures well in advance to install in their orchards timely. Some of the progressive farmers even purchased crude Methyl eugenol solution and prepared their wooden blocks lures own their own with the help of KVK. Now the technology is not new for progressive farmers and exporters of mango in the district.
Further, farmers are now being trained to lower the cost of the technology by making homemade traps. Used mineral water or soft drinks bottles may be utilized with four windows of $1.5 \mathrm{~cm}$ diameter.

The wooden blocks should be placed almost at the same level of the windows. The use less plastic water/soft drinks bottles are also performing well. Farmers may purchase only lures to be recharged in the home made traps. Since the technique employed is male annihilation technique, the population of the pest will automatically decline in future. The technology is being proved highly beneficial for the farming community which were otherwise employing blanket application of insecticides and getting poor yield due to heavy fruit fly attack in Meerut district. Certainly, farmers are getting higher yield and increased income resulting improved life style and better socio economic status. Scientists of the centre are now popularizing the home made traps among mango growers for maximum adoption of the technology by lowering its cost. 